\title{
Analyzing Cultural Artifacts for the Introduction, Perpetuation, or Reinforcement of Moral Ideals
}

\author{
Jennifer Williams \\ Assistant Professor \\ Texas A\&M University \\ dr.jen@tamu.edu
}

\begin{abstract}
The development and socialization of morals is a complex concept for students studying ethics. To help students understand the role social learning theory plays in the development of morality, an activity was created focusing on cultural artifacts and their introduction, perpetuation, and/or reinforcement of morality. The aim of this assignment is for students to see "the dialogue between cognitive structure and the complexity presented by the environment" (Kohlberg \& Hersh, 1977, p. 57). Results for this assignment not only showed improved conceptualization of moral development by students, but also engaged their higher-order thinking skills.
\end{abstract}

\section{Introduction}

When discussing how our moral compasses form as well as moral development, students are quick to identify parents and peers as influential factors. They tend not to realize the complexities that social learning theory plays on moral development. While some moral theorists would argue of our innate capabilities to discern right from wrong and good from bad, the majority of moral development theorists would argue we are socialized into our dominate moral philosophy (Pojman \& Fiser, 2009).

To aid students in their self-discovery of moral development, an activity was developed which asks them to look for an example of how morals are introduced, perpetuated, or reinforced within a culture (broadly defined). The objectives for the activity are:

1. identify an artifact which introduces, perpetuates, or reinforces moral ideals

2. research the origin of the artifact

3. analyze the application of the artifact in terms of socialized moral development

4. correlate the artifact to Kohlberg's stages of moral development 
The aim of this assignment is for students to see "the dialogue between cognitive structure and the complexity presented by the environment" (Kohlberg \& Hersh, 1977 , p. 57). Students are asked to reflect on their experiences as well as look to other cultures to find their examples. In this regard, they are using their existing cognitive structures in regards to morality and seeing how the artifact interacts with the culture (environment). By utilizing diverse artifacts, and then presenting said artifacts to the rest of the class, students begin to acknowledge the complexities of moral development (or acknowledging how complex it is to build a moral compass).

\section{Background}

In the current neo-charismatic leadership paradigm, morality is a central issue in leader development. The link between morality and leadership goes beyond authenticity and values based leadership. Studies link moral development with leadership traits and show how personality dichotomies can be used in diagnosing moral developmental levels (Narvaez, Lapsley, Hagele, \& Lasky, 2006). Studies of the associations between morality and motivation as well as leader behavior and morality have shown correlations (Narvaez \& Lapsley, 2009). Because of this, morality and leadership are exceedingly intertwined. It is imperative for students to understand not only how the two concepts coincide but also how each are developed.

Moral development as defined by Piaget and enhanced by the research of Kohlberg, "represents the transformations [morality] that occur in a person's form or structure of thought" (Kohlberg \& Hersh, 1977, p. 54). Kohlberg's three stages of moral development; preconventional, conventional, and postconventional, occur invariant sequence with movement forward through the stages. Kohlberg and other theorists have proven a correlation between moral development and Piaget's model of child development. Other theorists have drawn from social identity theory to describe moral development. This idea of moral identity "can be organized around traits associated with moral behavior" (Reynolds \& Ceranic, 2007, p. 1611). Thus, ethical relativism has a direct impact on moral development. "Frequent and consistent experiences with a specific domain of social behavior" (p. 968) has a direct correlation with subscribed moral actions (Narvaez, Lapsley, Hagele, \& Lasky, 2006). For this reason, it is essential for students to understand the role of context and culture in morality. Looking at artifacts is one way to understand this level of culture.

Using an activity which asks students to use their higher-order thinking skills to examine moral development will not only increase their knowledge of moral 
development but will also enhance their moral development and allow them to utilize Kohlberg while leading. Synthesis, application, and active participation are important in using higher-order thinking skills in exercises in leadership and morality (Williams \& Coers, 2009). Mayhew, Seifert, Pascarella, Laird, and Blaich (2012) found the use of this type of pedagogical methodology increases moral reasoning among college students.

\section{The Assignment}

The origins of this assignment can be traced back to a children's book. While reading The Berenstain Bears and the Golden Rule, (name) realized how many of her child's books truly have "a moral" to the story. (name) then began to look at how other non-traditional teaching methods are utilized to socialize moral development. After finding connection after connection between moral development socialization, and cultural relativism, (name) thought her students would benefit from such an analysis. Thus, an activity for moral development was developed.

This assignment asks students to identify an artifact that introduces, perpetuates, or reinforces moral ideals of a culture. They are challenged to look reflexively at their own upbringing as well as to diverse cultures to find examples. This allows students to combine previous leadership training and education to enhance their leadership and moral development (Brungardt, 1996).

Because of the impact of relativism in the development of moral identity, it is important for students look at moral development through the lens of organizational culture. Schein (2004) notes when looking at organizations, the first level of analysis includes artifacts. After artifacts are identified, students can then begin discussing the underlying values and beliefs of the culture. Artifacts are the phenomena one sees, hears, and feels" (p. 25) when diagnosing culture. Artifacts can also include "physical environment, language, technology, artistic creations, style as embodied in clothing, manners of address, emotional displays, and myths and stories told" (pp. 25-26). This was also the inspiration of the assignment.

The activity is introduced by reading The Berenstain Bears and the Golden Rule to the students. At first, they laugh and then they begin to remember those books they read as children and young adults, which had an impact on their development. A facilitated discussion follows giving other examples (commercials for after school specials are shown along with a cartoon version of Aesop's Fables) in which students can begin a dialog about how moral compasses develop. 
In groups, students are given time in class to brainstorm artifacts. There are a couple we have told them were "too obvious" and not let them use for their final paper and presentation. Those include the (university) code of honor statement, religious texts, and any item we have discussed during class. They are then assigned their project. Groups are given a week to find their artifact and complete the assignment.

The assignment manifests into a presentation that asks the groups to:

- Introduce their artifact

- Explain how their artifact either introduces, perpetuates, or reinforces either morality or ethics

- Research the underlying theory (ex: who came up with the golden rule for Sister Bear)

- Explain the social ramifications of their artifact

- Correlate the artifact to Kohlberg's stages of moral development. Which does it target and how does it help one move to the next level.

The presentations are five to ten minutes with time for questions upon completion. Students are encouraged to bring in examples of their artifact (if applicable) or present in an "edutainment" manner (enhanced creativity and active learning by the participants). Students also submit an outline of their information with proper references.

\section{Results}

By asking the students to identify, analyze, and apply their artifact to the socialized moral development of a culture, they are engaging in higher-order thinking which, as Mayhew et. al (2012) found increases the moral identity development of the student. Students also are quick to identify the cultural relativism, which exists within each artifact and how it is used to introduce, perpetuate, or reinforce morality.

This activity has been used in five semesters of "Leadership and Ethics." Each semester has given diverse but always interesting artifacts. One group identified fortune cookies as an ethical artifact. They researched and found the original fortune cookies relied on Confusion ethical statements as their fortunes. They brought cookies for the class and had them open and read the fortune inside and then compare it to moral philosophy. Another group showed clips from TV show from the 50s-present day displaying the relationships between women and men. They showed how we have gone from a married couple not being able to share a bed, on television, to 16 year olds having children and their own reality show. 
They related it back to not only leadership movements but also political movements. The Foundation for a Better Life has been used two semesters as an artifact. The students researched and found the foundation's commercials, displaying values and moral behavior, are specifically run during certain times of the day as well as during specific shows to target behavior.

\section{Recommendations}

While this activity is used in an undergraduate course focusing on moral/ethical theories and their application to leadership, it could be incorporated into a course where there is a component of ethics.

If the activity is used in an ethics course where theory is learned, it is recommended to complete this activity toward the beginning of the course. Beginning the course discussion how we develop moral philosophies serves as an effective starting point. Students discussing how they view morality and where they learned right from wrong and good from bad lets them discuss their similarities and differences in cognitive structure. Having students discuss artifacts before the constraints of learning moral theory will allow them to think creatively.

It is also recommended to refer back to the artifacts as the semester progresses. For every moral theory discussed, there is usually at least one artifact, which displays that moral theory. For example, corporal punishment is a good example of social contract theory. At the end of the semester, students can look back on their artifacts and reflect on the impact each holds in introducing, perpetuating, or reinforcing moral ideals.

The activity has been completed with and without discussion of Kohlberg's developmental stages. If Kohlberg has been discussed, students can categorize their artifact as preconventional, conventional, or postconventional. By having the students categorize, they use higher-order thinking skills. 


\section{References}

Brungardt, C. (1996). The making of leaders: A review of the research in leadership development and education. The Journal of Leadership Studies, 3(3), 81-95.

Kohlberg, L., \& Hersh, R. H. (1977). Moral development: A review of the theory. Theory into Practice, 16(2), 53-59.

Mayhew, M. J., Seifert, T. A., Pascarella, E. T., Laird, T. F. N., \& Blaich, C. F. (2012). Going deep into mechanisms for moral reasoning growth: How deep learning approaches affect moral reasoning development for firstyear students. Research in Higher Education, 53, 26-46.

Narvaez, D., \& Lapsley, D. K. (2007). Moral identity, moral functioning, and the development of moral character. Psychology of Learning and Motivation, 50, 237-274.

Narvaez, D., Lapsley, D.K., Hagele, S., \& Lasky, B. (2006). Moral chronicity and social information processing: Tests of a social cognitive approach to the moral personality. Journal of Research in Personality, 40, 966-985.

Pojman, L. P., \& Fiester, J. (2009). Ethics: Discovering Right and Wrong $\left(6^{\text {th }}\right.$ ed.). Belmont, CA: Wadsworth.

Reynolds, S. J., \& Ceranic, T. L. (2007). The effects of moral judgment and moral identity on moral behavior: An empirical examination of the moral individual. Journal of Applied Psychology, 92(6), 1610-1624.

Schein, E. H. (2004). Organizational Culture and Leadership $\left(3^{\text {rd }}\right.$ ed). San Francisco, CA: Jossey-Bass.

Williams, J., \& Coers, N. (2009, July). Ideas for using public pedagogy (popular media) to teach leadership. Round table presentation presented at the annual meeting of the Association of Leadership Educators, Providence, RI. 


\section{Author Biography}

Jennifer Williams is an Assistant Professor of Leadership at Texas A\&M University. She teaches undergraduate and graduate courses in leadership theory, team development, ethics, and organizational culture. Her research line of inquiry is pedagogy of leadership development. She is also the faculty director for the Dr. Joe Townsend '67 Leadership Fellows Program. 